\title{
AC 2007-2226: AN AUTONOMOUS APPROACH TO SAFE MACHINE TOOL OPERATION AND EDUCATION
}

Niall Seery, University of Limerick

William Gaughran, University of Limerick

Thomas Waldmann, University of Limerick 


\title{
An autonomous approach to safe machine tool operation and education
}

\begin{abstract}
On considering international competitiveness and economic sustainability, the dynamics and complexities of the workplace are more challenging now than ever before.

Consequently, a methodical approach to how students learn and construct meaning is becoming increasingly important in light of the demands put on graduate engineers.

Although engaging engineering students in a constructivist educational paradigm is desirable and ensures a 'deeper' learning experience, it is not always feasible. Two factors that traditionally mitigate against constructivist education within workshop practice are time constraints and health and safety.

This paper discusses a non-behavioural approach to educating engineering students on the key content and psychomotor skill development necessary to competently operate a milling machine. The strategic design focuses on a computer-facilitated machine-tool training partner that assists novice users in operating the milling machine. The approach was devised to facilitate the cognitive characteristics of engineering students at the University of Limerick, while ensuring a participative pedagogical paradigm.
\end{abstract}

Key Words: Learning Styles, Computer Assisted Learning, Engineering Pedagogy.

\section{Background}

In comparison to behavioural training, constructivist pedagogy often necessitates significant resource demands. These demands together with the complex logistics and time restriction associated with third level education encourage the adoption of a 'product' model to machine tool training. With the inevitable shift from the information (left-brain dominant) age to a more conceptual age where additional aptitudes are necessary, pedagogy must evolve to ensure continued growth ${ }^{1}$.

The pedagogical design discussed in this paper incorporates a novel application of data acquisition software to support students' knowledge constructs that adheres to the principles of 'constructive alignment' . Introducing students to a remotely operated milling machine encourages them to actively and safely experiment with a series of predefined machining tasks. This gives third level students the autonomy to become the masters of their own learning experiences in a non-traditional structure.

This is a significant in educational paradigm as students currently undertaking undergraduate courses are a product of an examination driven educational culture that appears to produce an apathetic student, motivated solely be extrinsic reward. The value of the learning activity and the quest for new knowledge, seem for many students to have regressed to a 'means-end' effect. The delivery and acceptance of information appears to be strongly rooted to the behaviourist paradigm, with student 'mimicking' cognitive involvement. 
Much research suggests that the use of a problem-based or project-based learning environments help motivate students to learn on a deeper level ${ }^{3,4}$. Student-cantered approaches to learning which focuses on active and cooperative learning indicate a positive correlation between the instrumental method and the students' engagement of a 'deep' learning approach ${ }^{5,6,7,8}$.

The design of the practical approach to machine tool training discussed in this paper is conceptually grounded on theories of participative education. Creating a pedagogically innovative learning environment to facilitate exploratory learning is a novel advance towards effective machine tool training.

\section{Methodology}

The research methodology encompasses three distinct phases, machining a prescribed component on the milling machine, an evaluation of the learning activity and finally a 'near' transferability exercise. The study employs the use of a control and experimental group with the later engaging in an augmented machine tool. The focus of the study is to examine student performance in key competencies and engage students in a subjective evaluation of the learning activity.

\section{Participants}

Participation was requested from the entire cohort of year one engineering students within the Manufacturing and Operations Engineering Department at the University of Limerick. Sixty four students participated in the study. The participants were randomly divided into a control and experimental, at no stage during the study were participants aware of which group they were in. Although random allocation of students to groups was employed, each group were stratified under the headings of Gender, student type (Mature/Undergraduate, and completion of Leaving Certificate Engineering (High School) to ensure homogeneity of data (Table 1).

Table 1 - Control and Experimental Groups

\begin{tabular}{|c|c|c|c|c|c|}
\hline Group & Total & Mean Age & STDEV & Female & Male \\
\hline Control & 35 & 19.02 & 2.83 & 5 & 30 \\
\hline Experimental & 29 & 19.17 & 5.7 & 5 & 24 \\
\hline
\end{tabular}

The Kolmogorov-Smirnov normality test was conducted and indicated a normal distribution for both participant groups.

\section{Design}

Practical experience

The initial phase of the research involved the design of the experimental apparatus. The focus on exploratory learning within the context of a potentially dangerous machine necessitated a design that was centred on three principle areas.

1. Control of machine operation

2. User safety

3. Overall Learning Experience 
An EMCO demonstration Milling Machine was chosen for the purpose of the experiment. A number of modifications were made to the machine; it was fitted with linear encoders and a digital display, together with additional manual and digital emergency stops.

Paramount to the success of an exploratory learning paradigm was the confidence of the user to explore. Special emphasis was put on creating a safe environment that allows the student to make mistakes, comparable to the Microsoft 'undo' philosophy. The machine tool was fitted with a safety guard that controlled the power to the spindle Controlling the machine tool in a remote fashion with the use of data acquisition software (Labview) added to student safety. The digital display was fitted to the 3 axes and controlled by either a GUI or a physical control panel (Figure 1). The objective of the machine was to enable students to explore the operations and processes of the milling machine in a safe controlled environment.

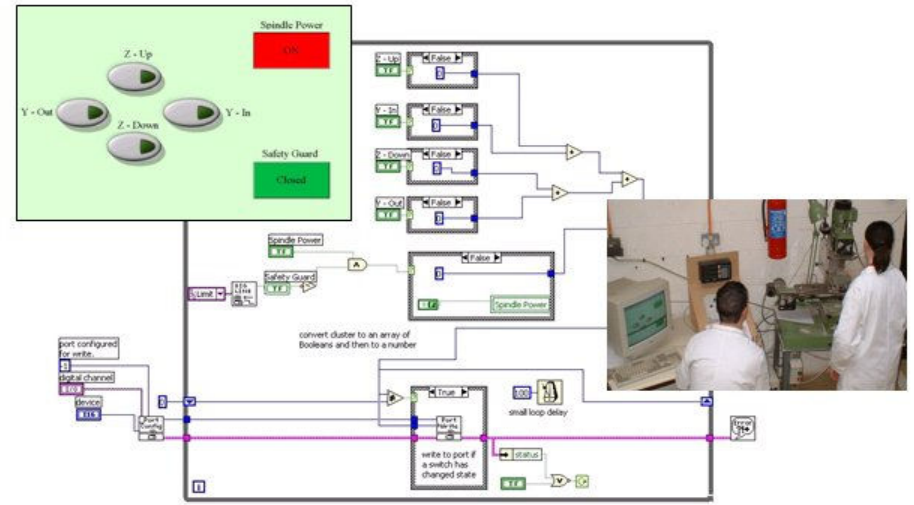

Figure 1 - Machine tool

Both 'push button' approaches were designed on the principle of 'affordance', which enabled the student to remotely control the X, Y, and Z. Students had the choice of which remote commands to use.

As it was necessary to focus the students on particular areas of exploration, a practical exercise was designed to include the following operations and tasks (Figure 2).

- Setting up of the work piece

- Changing the cutter

- Setting the datum

- End milling

- Cutting a slot

- Cutting a chamfer

- Cutting an internal slot

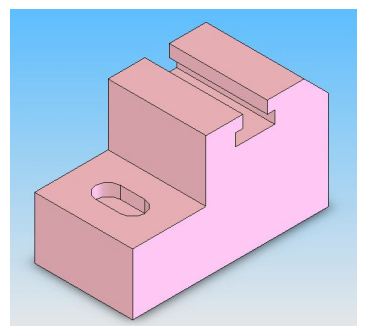

Figure 2 - Milling Exercise

A work piece material was selected on the basis that it was easily machined and yet portrayed the generic characteristics of a metal (eg - chip formation). A composite resin was selected as an appropriate material.

\section{Evaluation mechanism.}

As the use of the augmented milling machine was an unorthodox approach to introducing safe machine tool operation, it was important to evaluate the effectiveness and quality of the interaction and the exploratory experience and engagements of the participants in the experimental group. The validity of using two different questionnaires and drawing conclusive comparisons is questionable, ${ }^{9}$ therefore a purpose designed evaluation questionnaire was designed to explore key areas of the machining experience for the 
experimental group only. The questionnaire was comprised of both open and closed questions and also encouraged students to make additional comments on any aspect of their experience. A 5-point Likert scale was used to grade the level of satisfaction in seven key areas; user safety, ease of use, instruction, interface, discovery learning, reinforcement of theoretical content, and usability.

\section{Knowledge transferability}

The extent to which positive transfer occurs needed to be examined as subjective assessment was not a true indication of the quality and resultants of the learning experience. Both groups experienced distinctly different approaches to the practical aspects of the course. The exploratory unsupervised learning of the experimental group was significantly different to the technician-centred approach experienced by the control group. It was decided that drawing direct comparisons from the experiences of both groups would be misleading. A knowledge transferability experiment was devised; this experiment focused on 'specific', 'lateral' and 'near' transfer of the research material ${ }^{10}$. Five tasks were derived to correlate with the previously covered practical material. The final task requested participants to list appropriate processes and a manufacturing sequence for a purposefully designed transfer exercise. Students' performances were graded by a member of the technical staff who was unaware of the existence of control and experimental groups.

\section{Procedure}

\section{Practical experience - Control Group}

The approach for the control group replicated the traditional approach to machine tool tuition within the University of Limerick. Students were assigned an allotted time on the traditional milling machine. Then a didactic approach was employed to teaching the students (in pairs) prescribed content. Each group of students machined two cuts on a work piece as per the technician's instructions. All machine and work-piece set-ups were explained to the students but carried out for the most part by the technical staff. The duration of this machining exposure was approximately one hour.

\section{Practical experience - Experimental Group}

Students in the experimental group experienced an alternative approach to the practical element of the course. Students were allotted one hour on the augmented milling machine. A briefing was given on the operations of the remote controls. Students worked in pairs on a prescribed milling exercise. A task sheet was also given to each student, which focused the student's attention on specific areas of exploration. One component was machined per pair. Access to a web tutorial was also given to the students, but could not run simultaneously to the machining interface for safety reasons. Throughout the experiment students were observed from a distance.

\section{Evaluation of practical experience}

Only the experimental group evaluated the learning experience, as they engaged with traditional approach during machine tool training on other machine tools. On completion of the prescribed exercise on the augmented milling machine, each participant within the experimental group was requested to complete the evaluation questionnaire. Students 
were allocated fifteen minutes to complete all sections and encouraged to critically evaluate their experience.

\section{Knowledge transfer}

Three weeks following the original machining exercises, the entire cohort (control and experimental) participated in a transferability experiment. Each student was randomly called to the milling machine from his or her regular laboratory work. A member of the technical staff requested the student demonstrate each of the five predefined tasks. Students were observed and graded on their performance of each task. The duration of the transfer exercise varied from 15 to 25 minutes.

\section{Findings}

\section{Practical experience}

Only students from the experimental group were asked to evaluate the practical learning experience as the novelty of approach and interaction prevented the possibility of using a generic questionnaire. Participants responded to the practical milling evaluation questionnaire immediately after using the system. The evaluation gathered responses on the following area: User Safety, Ease of Use, Exploratory learning, reinforcement of theoretical knowledge and additional learning and usability issues.

The following issues emerged during the observations of the dynamics of each student exploration:

- Students became competent using the machine very quickly and the initial tool positioning errors were seldom repeated.

- The dynamics of paired learning facilitated the initial exploration and to some extent may have reduced the associate fear factor. On two occasions it was necessary to have a group of three students using the apparatus. This assisted the development of a passive student, as on both occasions one student did not take any meaningful part of the exploration. The dynamics of the three-student group quickly facilitated a more dominant leader.

- Student discussions focused on the strategic manufacture of the component and the cutting process rather than the operation of the machine. Following the initial cognitive adaptation of the exploration, whether by assimilation or accommodation, students quickly affirmed their attention to the task at hand. The presence of the technology quickly became irrelevant as the learning process took precedence, similar to the work of Hall ${ }^{11}$.

- All student groups completed the task within the allotted time and a sense of achievement was evident on submission of the completed task (emotional experiences difficult to measure and quantify).

Drawing comparisons between the groups experiences would consequently be somewhat meaningless. Participants from the experimental group evaluated their experience via a purpose-designed questionnaire. All participants felt the approach was beneficial as an introduction to milling. Students rated seven key features of the approach as illustrated in Figure 3. 




Figure 3 - Means scores of perceptual evaluation

On average students found the listed features very satisfactory $(4=$ good and $5=$ very good on the Likert scale). Of particular interest is the students rating of user safety. As this was a key consideration in the exploratory learning approach, it should be noted that there was little or no anxiety in relation to user safety. Surprisingly the quality of instruction was rated highly as this came primarily in the form of a task sheet, although it was supplemented by a theoretical website. Also the graph illustrates a positive response from the students on their rating of how the intervention reinforced the theoretical knowledge. The positive response to the theoretical constructivist concept was suggestive of a meaningful learning experience.

The success of the learning environment was emphasised by the unprompted positive student responses. From the 29 respondents, 28 indicated that they would find this approach beneficial in supplementing other machine tool training. Those in favour of the approach described it as "enjoyable", "interesting", "it is easier to learn by doing!" and "it assists in thinking about how milling is performed". However, when asked if students would like the approach to replace the existing structure of the practical labs, just over $62 \%$ responded positively. Negative respondents emphasized the need for a balanced educational approach, "I feel you need a bit of both to make the learning experience viable." Another student claimed, "One needs instruction to gain knowledge." Students were encouraged to give additional comments on the overall pedagogical approach. The high rate of response in the additional comments section was encouraging, as more than 93\% of students gave additional feedback. The following comments are representative of the student's independent observations:

- "It was very good, learned more about milling in ten minutes than I'd taken in, in an hour." 
- "I found it useful in supporting the theory we had already studied and it makes a good visual experience as you can relate to the subject more."

- "Enjoyable. Wasn't being rushed. Like in the lab, with people queuing behind me."

An interesting observation and comment made by one student, was that "the material used was easy to work with". When discussed in the context of the inclusive practical learning environment, the material plays an important part in the student's perception and experience of the learning activity. This is best explained in the Reggio approach, where the learner is immersed in an environment that is seen as a 'pedagogist', as the physical environs, components and material properties play an influential role in the learning activity. Brookes and Hardy (2002), explain that this pedagogist role should not be underestimated as they consider it as influential as a "third Teacher" ${ }^{12}$.

Interestingly during one of the focus group interviews a failing of the pedagogical approach was identified by one of the students (A Mature student who originated from a craft background and had a number of years industrial experience as a tool-maker prior to undertaking his undergraduate course of study).

"Well, from my own experience I found it very, very awkward because I was use to the real thing [milling machine] and, I had no control over the axes, which I'm used to. When finding the datums you had no way of touching an edge, you have no fine controls to bring it in really, so you're into the piece and I didn't like it, it didn't feel right. Because I was used to using an actual one with a manual control"

This raises a concern about the lack of facility for the bodily/kinaesthetic intelligence. However, this student did also go on to say:

"I like the idea because it is safe and you can't really do anything wrong. You're not near anything, your pressing the controls and you're a safe distance away. You can't wind it too fast or too slow. It's controlled and its safe and it will build up your confidence with it. On that score it would be good. It would be good as an introduction, to tool work, attending tool changes you know it does the job."

The theoretical basis for contextualising the issues that emerged from the practical exploration is best encapsulated by the work of Taylor ${ }^{13}$. This work identifies a paradigm of effective learning that incorporates the unique interactions between the cognitive, affective and psychomotor learning domains ${ }^{13}$.

\section{Knowledge transferability}

The quality of student learning in relation to practical machining and experience could not be assessed adequately by a theoretical examination. A knowledge transfer experiment was conducted to evaluate the level and type of transfer. All participating students were allocated specific times on the Bridgeport Milling machine under the supervision of an experienced technician (The same technician was used for the duration of the study to ensure consistency). The examining technician was not familiar with the participants and like the students was not aware of which participants were assigned to 
the experimental group and which were in the control group, thus eliminating the corruption of data due to the Placebo effect.

The transferability experiment assessed the student's ability to perform five predefined tasks. The approach to the experiment focused on specific, lateral and near transfer. Participants from both the control and experimental groups were assessed and scored on a five point Likert scale. Performance results in the assessment are illustrated for both cohorts in Figure 4.

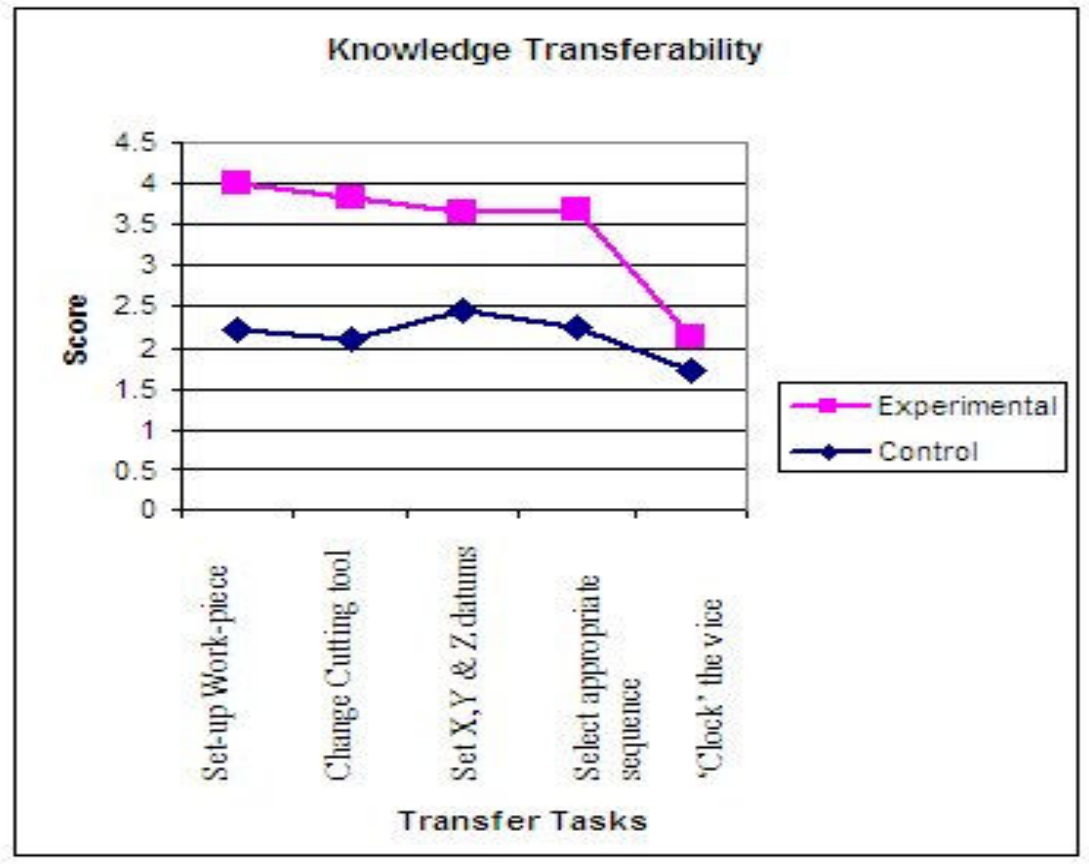

Figure 4 - Group performance on transfer tasks

Scores were ranked for both groups and analysed for statistical difference. Significance value and mean scores are tabulated in Table 2 and Table 3.

Table 2 - Knowledge Transfer between groups

\begin{tabular}{|l|c|c|c|c|c|}
\hline \multicolumn{2}{c}{ Sum of Squares } & \multicolumn{1}{c}{ df } & Mean Square & F & Sig. \\
\hline Between Groups & 989.660 & 1 & 989.660 & 45.191 & .001 \\
\hline Within Groups & 1357.777 & 62 & 21.900 & & \\
\hline Total & 2347.438 & 63 & & & \\
\hline
\end{tabular}

Table 3 - Mean scores for knowledge transfer between groups

\begin{tabular}{|l|c|c|c|}
\hline Group & \multicolumn{1}{c}{ Mean } & \multicolumn{1}{c|}{ N } & \multicolumn{1}{c|}{ Std. Deviation } \\
\hline Control & 10.51 & 35 & 5.527 \\
\hline Experimental & 18.41 & 29 & 3.376 \\
\hline Total & 14.09 & 64 & 6.104 \\
\hline
\end{tabular}




\section{Discussion}

The control group experienced a technician-centred approach to the practical laboratory session; however this was not an intentional means of disadvantaging the control group, but the research approach focused on a non-interference with the traditional methodology. The cognitive engagement of students was limited as the pedagogical approach was reduced to a 'drill and practice' model, with the sole purpose being student progression to the next process. Observations and evaluations of student experiences of the techniciancentred approach were conducted for a number of the control group sessions. Students were heavily guided through the process and did not engage in the set-up or strategic approach to manufacture. Each student followed the direct instruction by the technician, and deviation was quickly reprimanded. The 'conveyer belt' of students filed through the processes, developing at most a 'surface' approach to the learning experience.

\section{Pedagogical innovative approach}

Based on Kolb's cycle of experimental learning ${ }^{14}$, the concrete experience and active experimentation were facilitated by a pedagogically innovative approach to machining. The augmented reality, experienced by the experimental group allowed students to engage in a safe exploratory learning environment. Students' safety was paramount and every intervention was implemented to ensure the safety of the user.

The practical approach adds a significant paradigm to engineering faculties' repertoire of practical pedagogical tools. In stark contrast to the 'drill and practice' educational paradigm, the augmented milling machine encouraged students to engage in a unique exploratory learning environment. Students explored the necessary 'how' and the elusive 'why' that predicates an effective learning experience. Incorporating the preferential styles of engineering students ${ }^{15}$ and the fundamentals of Piagetian philosophy, the experimental approach reached a new level in developing exploratory and participative learning.

Students were randomly paired for the laboratory session, the rationale for this approach stemmed from the necessity to reduce the anxiety of the student. As they were faced with the novel role of the autonomous learner, use of an unfamiliar machine tool and lacked the 'comfort blanket' of technical supervision (Figure 5\& 6). Based on piagetian cognitive development theory, cognitive growth depends on the presence of a

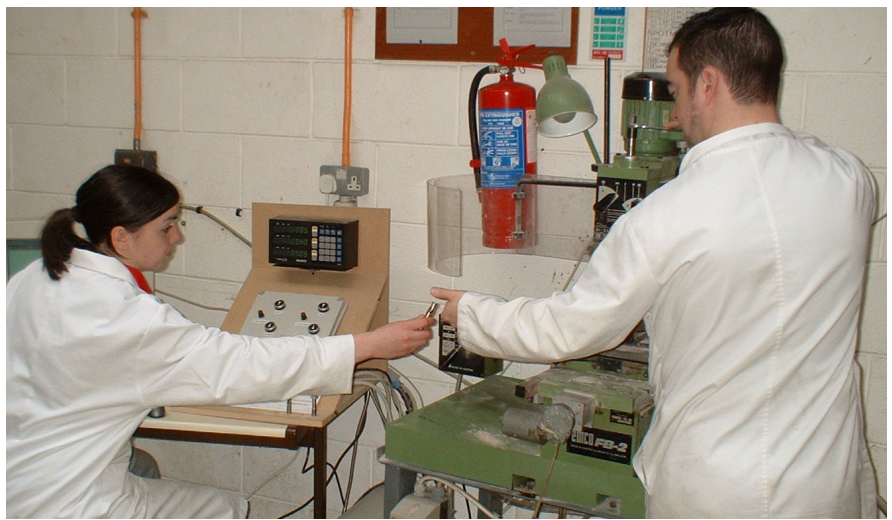

Figure 5 - Cooperative education during practical exploration 'disequilibrateing' stimulus that the learner is motivated to eliminate ${ }^{16}$. This approach incorporates the stimulus and forces the predictable process of 'equilibraiton' (the student's ability and the nature of the experience predicate this intellectual process). The collaborative learning environment of peer learning also fosters a deeper approach to learning, with the advantages of increasing 
the student's ability to analyse concepts, attain higher levels of achievement, and develop a more positive attitude towards the material being studied. The following pictures illustrate student engagement in the practical exploration of the novel pedagogical approach.

Students were guided by the task sheet and working drawing. They quickly explored the machine tool and collaborated to devise a strategic approach to the manufacture of the exercise. Each session was observed by the researcher, however there was little or no guidance sought or volunteered during the course of any of the practical sessions.

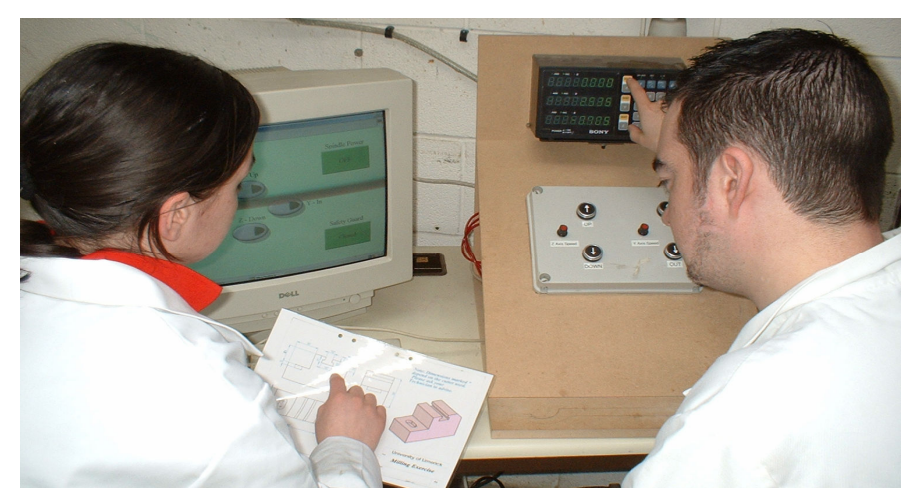

Figure 6 - Student collaboration in devising a strategic approach to manufacture.

\section{Knowledge Transferability}

The performance differential of participant students in both groups is evident from the graphical representation of performance measures. The poor performance of both groups on task five (explain and demonstrate "clocking the vice") was noticeable. This was the only section of the practical approach that was delivered didactically to the experimental group. Although this task was explained to all students the majority claimed never to have even heard of it. Overall students in the experimental group performed significantly better $(\mathrm{p}=0.001)$ than the control group.

There are no clearly defined subdivisions in the category of near transfer; however it should be noted that although the task is different from the learned task for the control group the machine tool was the same. This was not the case for the experimental group as both the process and machine tool was different from their learning experience. Although, still classified as near, it was not as 'near' as for the control group, and yet a significant difference in performance was recorded. In light of the fact that knowledge transfer is seen as evidence of true understanding. It can be derived that the experimental group had a superior understanding of the practical material than the control group, and therefore a more meaningful learning experience.

\section{Conclusion}

Aside from the theoretical philosophies of countless educationalists and scientists, this research study captures the essence of effective learning, combining aspects of the three primary learning taxonomies (Cognitive, affective and psychomotor).

As learning is not something that just happens to a student (Skinnerism) but something, which they themselves make happen by the means in which they formulate and apply new information. Therefore unambiguous learning should be based on instructional conceptualism (cognitive) opposed to the operant conditioning model, as Bruner argues there is a serious lack of emphasis on the process between the stimulus $(\mathrm{S})$ and the behaviour $(\mathrm{B})$ in the behaviourist paradigm ${ }^{17}$. 
On examination of the research data, it is evident that the experimental group engaged in a more effective learning experience and demonstrated significantly higher performances on the acquisition of knowledge, transformation, and manipulation of information, and application and demonstration of understanding.

\section{References}

1. Pink, Daniel. (2005) A whole new mind: How to thrive in the new conceptual age, New York, River head Books.

2. Biggs, J. (2003). Teaching for Quality Learning at University. Buckingham.

3. Dochy, F., M. Segers, et al. (2003). "Effects of Problem Based Learning: A Meta Analysis." Learning and instruction Vol 13: pp 533-568.

4. Duch, B. J., S. E. Groh, et al. (2001). "The Power of Problem-Based Learning, Sterling."

5. Felder, R. M. and B. R. (2003). "Learning by Doing." Chemical Engineering Education Vol 37.

6. Johnson, D. W., R. T. Johnson, et al. (1998). Active Learning: Cooperation in the college Classroom. Edina Minn, Interaction Book Co.

7. Trigwell, K., M. Prosser, et al. (1998). Improving Student Learning Through a focus on the Teaching Context. Improving Student Learning, Oxford.

8. Trigwell, K., M. Prosser, et al. (1999). "Relations between Teachers Approaches to Teaching and Students Approaches to Learning." Higher Education Vol 37: pp 57-70.

9. Cohen, L. Manion, L. and Morrison K. (2000) Research Methods in Education. London, Routledgefalmer publishers.

10. Gick, M. L. and K. J. Holyoak (1987). The cognitive basis of knowledge transfer. Transfer of Learning: Contemporary Research and Applications. S. M. Cormier and J. D. Hagman. London, Academic Press.

11. Hall, Anthony Michael Peter (2004). "Disappearing technology, emerging interactivity : a study of the design of novel computing to enhance children's learning experience in museums". Thesis (Ph.D.) - University of Limerick

12. Brookes, N. \& Hardy, A. (2002) The Craftplay Approach to Reggio Emilia. In Journal of Education in Museums. 2002 (23).

13. Taylor, M. (1990). Effectiveness in Education and Training: the theory and practice of personal development. Hants, England., Gower Publishing Company Ltd.

14. Kolb, D. A. (1984). Experiential Learning: Experience as the Source of Learning Development. Eaglewood Cliffs, Prentice Hall.

15. Felder, R. M. (1996). "Matters of Style." ASEE Prism.

16. Snowman, J. and R. Biehler (2000). Psychology applied to teaching (10th Ed.). Boston, Houghton Mifflin.

17. Fontana, D. (1995). Psychology for Teachers, McMillian Press. 